\title{
Investigation of the Effect of Process Parameters and Kinetics on Sulphuric Acid-Sodium Hydroxide Catalyzed Transesterification of Mango Seed Oil
}

\author{
Harrison C. Idimogu, J.A. Okeke, R. E. Chukwumalu \\ Chemical Engineering Department, Nnamdi Azikiwe University, Awka, Nigeria
}

\begin{abstract}
Fatty acid ethyl ester synthesized by transesterification reaction of triglycerides with alcohol is a contemporary energy source that has gained the attention of many researchers due to various benefit associated with its usage. This research focused on the production of fatty acid ethyl ester from mango seed oil through transesterification reaction using acid-base catalytic method. It was observed that the maximum reaction rate was obtained at a stirrer speed of 500rpm, catalyst concentration of $1 \%$ and ethanol/oil molar ratio of $6: 1$ after a reaction time of 1 hour. The results showed that the yield of ethyl ester increased with increase in molar ratio up to 6:1 and at a temperature of $65^{\circ} \mathrm{C}$ for the reaction time of 1 hour, the molar ratio of $6: 1$ of ethanol/oil is the best condition for transesterification reaction of mango seed to biodiesel fuel. The kinetics of transesterification reaction was also investigated and its parameters showed that the reaction followed a second order with an overall rate constant 3.9 $\times 10^{-2}(\% \mathrm{wt} / \mathrm{wt} \mathrm{min} \circ \mathrm{C})^{-1}$ and a regression value of 0.9504 . The activation energy for the reaction was estimated to be $94.23 \mathrm{~J} / \mathrm{mol}$. The properties of the fatty acid-ethyl ester met the requirement for ASTM D6751 and EN 14214 standards for biodiesel. This implies that the biodiesel produced from mango seed oil using ethanol, a $100 \%$ renewable energy source is of acceptable quality and can be substituted for fossil-based diesel.
\end{abstract}

Key Words: Mango seed oil, transesterification, kinetics, fatty acid ethyl ester, Sulphuric Acid-Sodium hydroxide.

\section{INTRODUCTION}

A $s$ the current crude reserves are progressively diminishing, clearly the cost of petroleum-based products will continue increasing and their imports will put an expanding trouble on public economies, which will at last give a chance to the development of sustainable power utilization. Among sustainable power assets, biodiesel is getting logically more significant because of its generally basic methods of production [13]. Other renewable source of alternative fuel is bioethanol which have proven to be effective produced from renewable feedstock such as agricultural and forestry residues [5]. Petroleum-based fuels are non-renewable, non-biodegradable and emit toxic gases such as oxides of sulfur, nitrogen and carbon which are the main causes of pollution and global warming. At present, the world depends mainly on petroleum fuels for generating power, transport, agriculture, for domestic uses and industrial activities [6]. The decrease of world petroleum reserves and environmental pollution caused by petroleum- based fuels have necessitated exploring alternative sources of energy.
The production and use of biodiesel have increased notably in many countries around the world using numerous feedstock sources. Unfortunately, it is only emerging in many African countries. Over the past decade, transport fuels utilization in Sub-Saharan Africa has increased at a rate of about $7 \%$ per year in line with increased economic activity [14]. This has had a huge economic effect on about thirty-five crude oilimporting countries in Africa.

One of the potential sources of biodiesel production is the Mango seed oil from mango tree (mangifera indica). Mango seed oil contains $37-55 \%$ of fats; it is composed mainly of eleven fatty acids, palmitic, margaric, linoleate, methyl stearate, capric and lauric acid etc, which together account for $85-99.85 \%$ of the total fatty acids [11]. Soft mango seed contains high palmitic acid content [3]. The physicochemical properties of mango seed oil are comparable with the properties of groundnut oil which has been used in biodiesel production [15].

Several methods have been used in the synthesis of biodiesel from vegetable oils and animal fats. However, there is a dearth of information on the production of biodiesel from mango seed oil and where such exists, they are insufficient. Also, mango seed is cheap and readily available. There is great competition between the edible oils for industrial products manufacture such as soaps, creams etc. and they are used for renewable synthesis hence more research centers on the use of non-edible for renewable fuel production, therefore, the interest in mango seed oil as a non-edible oil for biodiesel production. According to [1] biodiesel fuel from rapeseed oil was prepared in supercritical methanol to study the effect of reaction temperature, reaction pressure and molar ratio of methanol to triglycerides in the methyl esters formation. The results revealing that the supercritical treatment of $350{ }^{\circ} \mathrm{C}$, $30 \mathrm{MPa}$ and $240 \mathrm{sec}$ with molar ratio of $4: 2$ in methanol is the best condition for transesterification reaction of rapeseed oil to biodiesel fuel.

Ref. [7]) revealed that the methanolysis of soybean oil in the presence of $1 \mathrm{~mol} \%$ of $\mathrm{H}_{2} \mathrm{SO}_{4}$ with an alcohol/oil molar ratio of $30: 1$ at $65^{\circ} \mathrm{C}$ takes 50 hours to reach complete conversion of vegetable oil $(>99 \%)$ while the butanolysis (at $117^{\circ} \mathrm{C}$ ) and ethanolysis (at $78^{\circ} \mathrm{C}$ ) using the same quantities of catalyst and alcohol, take 3 hours and 18 hours respectively. The 
alcohol/vegetable oil molar ratio is one of the main factors that influence the transesterification reaction.

Fatty acid ethyl ester serves as an essential substitute and alternative to petroleum- based diesel. However, among other fuels derived from petroleum sources, mango seed oil was investigated as a possible feedstock to biofuel production to limit the use of petroleum-based diesel. The main objective of this research work was to investigate the effect of process parameters and kinetics on acid-base catalyzed transesterification reaction of mango seed oil.

\section{MATERIALS AND METHODS}

\subsection{Materials}

Fresh Mango seeds were bought from Eke Awka market, Anambra State. Electronic weighing balance (serial number; (S09B035B, model number; Yp-1002N), Ethanol and Sodium hydroxide were purchased from Onitsha. Other reagents were of analytical grade were also purchased from Onitsha.

\subsection{Methods}

Seed preparation: The seeds were dehulled to remove the outer seed coat. The dehulled seeds were then spread and dried in the sun for three consecutive days to reduce the moisture content present in the seed. The seeds were further dried using an oven for 2 hours, the results of moisture content of mango seed are as shown in Table 1.

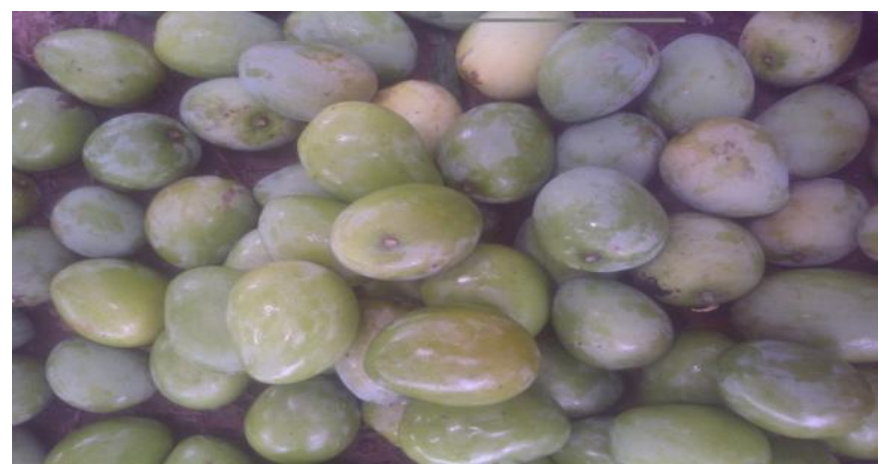

Fig 2.0: Mango Fruits

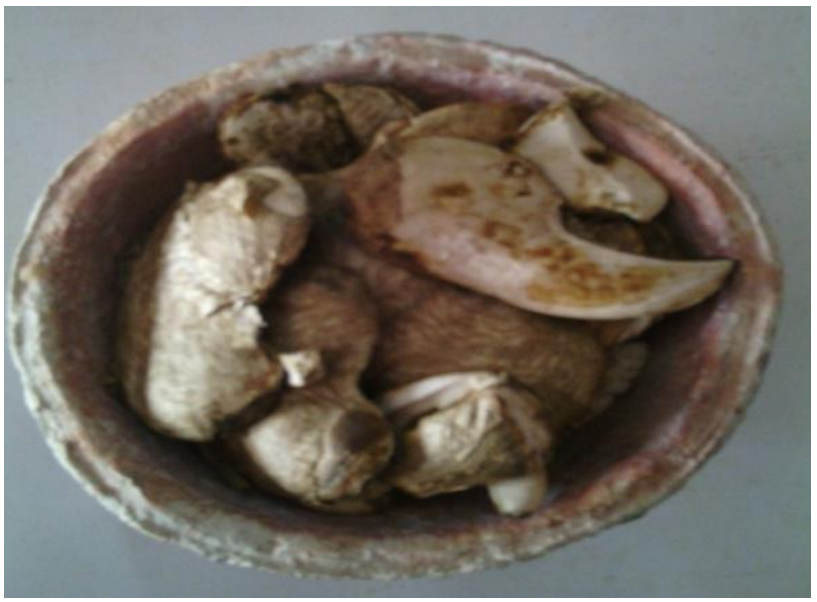

Fig 2.1: Dehulled Mango Seed in a Petri Dish.
2.3 Oil extraction: Oil extraction was carried out using Soxhlet extractor. $300 \mathrm{ml}$ of $\mathrm{n}$-hexane was poured into a distillation flask and placed on a heating mantle. 30 grams of the sample was placed in a porous sack and inserted in the Soxhlet apparatus which was inserted into a three-neck pot equipped with a reflux condenser on one of the necks, the second neck was equipped with a thermometer while the third neck was tightly covered. The reflux condenser was used to return the condensate to the three-neck pot as the heating proceeded. The heating mantle was set at a temperature of $65^{\circ} \mathrm{C}$. The whole set up was observed for 6 hours and later dismantled and the full miscella (oil + solvent) was distilled to obtain the oil. The mass of the cooled oil was obtained as the difference between the weight of the evaporating dish with oil and weight of the empty evaporating dish. Standard analysis was then carried out on the oil extracted to determine the chemical properties.

2.4 Characterization of mango seed oil: Physicochemical Properties of the extracted mango seed oil were obtained from Gas Chromatograph and the results were showed in table 3.0.

2.5 Neutralization of mango seed oil: $1.525 \mathrm{M}(6.1 \% \mathrm{w} / \mathrm{v})$, $1.925 \mathrm{M}(7.7 \% \mathrm{w} / \mathrm{v})$ and $2.025 \mathrm{M}(8.5 \% \mathrm{w} / \mathrm{v})$ concentration of sodium hydroxide were added to the extracted mango seed oil to neutralize the free fatty acids and additional concentration of $0.1 \mathrm{M}(0.4 \% \mathrm{w} / \mathrm{v}), 0.15 \mathrm{M}(0.6 \% \mathrm{w} / \mathrm{v})$ and $0.2 \mathrm{M}(0.8 \% \mathrm{w} / \mathrm{v})$ of sodium hydroxide were added as well to ensure complete soap formation. This was followed with stirring at $50^{\circ} \mathrm{C}$ originally, and immediately the sodium hydroxide was added, the temperature was increased to $60^{\circ} \mathrm{C}, 70^{\circ} \mathrm{C}$ and $80^{\circ} \mathrm{C}$ at reaction time of 30 minutes, 40 minutes and 50 minutes. The soaps formed were separated by centrifugation at 2000rpm. The oils obtained in the previous stages were washed severally by adding $15 \%$ of pure water at $95{ }^{\circ} \mathrm{C}$ to remove the traces of soaps dissolved in the treated water and the remains of unreacted sodium hydroxide that was added. The neutralized mango seed oil was then transferred into a $250 \mathrm{ml}$ beaker and heated to remove the wash water and the neutralized oil was obtained.

2.6 Synthesis of mango seed ethyl ester (Transesterification reaction): $25 \mathrm{ml}$ of the neutralized mango seed oil was transferred into a beaker of $250 \mathrm{ml}$ and heated to remove any form of water that must have condensed in the oil during neutralization with an alkali, sodium hydroxide $(\mathrm{NaOH})$ precisely. A certain volume of ethanol $(5.51 \mathrm{ml})$ obtained from ethanol/oil molar ratio of 6:1 was poured into a one necked round bottom flask. $0.0476 \mathrm{~g}$ of sodium hydroxide catalyst, $\mathrm{NaOH}$ (1\% of the catalyst weight) was added as well and finally, the heated oil was added and the one necked round bottom flask was tightly covered. The three-neck pot was then inserted into the electric stirrer at a constant speed of agitation of 500rpm and the temperature of the thermostatic water bath was set at $50^{\circ} \mathrm{C}$. This was left to react for 1 hour after which the solution was transferred into a separating funnel and the reaction product was allowed to settle into two phases for 30 minutes. The bottom dark brown section of the 
separating funnel which is glycerol was decanted while the upper amber yellowish layer, ethyl ester was left in the separating funnel. Tetraoxosulphate (iv) acid $\left(\mathrm{H}_{2} \mathrm{SO}_{4}\right)$ was added to the collected biodiesel, followed by warm water wash to remove impurities. The washing was repeated until no trace of glycerol found and final product dried in an open beaker on a hot plate. The yield of the ester produced was measured. The experiment was repeated setting the temperature of the water bath at varying temperatures of $55^{\circ} \mathrm{C}$ to $75^{\circ} \mathrm{C}$ at a molar ratio of ethanol/oil of $6: 1$, stirrer speed of $500 \mathrm{rpm}$ and catalyst concentration of $1 \%$ of catalyst weight $(\mathrm{NaOH})$ for one hour each. The transesterification procedure was repeated for various catalyst concentration range of $0.5 \%$ to $1.75 \%$, varying stirrer speed of $400-600 \mathrm{rpm}$ and ethanol/oil molar ratio of $3: 1$ to $15: 1$. The effect of these process variables on the yield of biodiesel are shown in Fig 3.0, 3.1, 3.2 and 3.3.

2.7 Effects of process parameters on biodiesel yield: A set of experiment were carried out to study the effect of process variables on the biodiesel yield, these parameters include; reaction temperature, stirrer speed, catalyst weight and molar ratio of ethanol to triglycerides in the ethyl esters formation. Table 2.0 below summarizes the variation of different process variable conditions on biodiesel yield.

Table 2.0: Process variable condition used in the study

\begin{tabular}{|c|c|c|c|c|c|}
\hline Process variables & 1 & 2 & 3 & 4 & 5 \\
\hline $\begin{array}{c}\text { Temperature (deg. } \\
\text { C) }\end{array}$ & 55 & 60 & 65 & 70 & 75 \\
\hline Molar ratio & $3: 1$ & $6: 1$ & $9: 1$ & $12: 1$ & $15: 1$ \\
\hline Stirring speed(rpm) & 400 & 450 & 500 & 550 & 600 \\
\hline $\begin{array}{c}\text { Catalyst loading } \\
\text { (wt } \%)\end{array}$ & 0.75 & 1.00 & 1.25 & 1.50 & 1.75 \\
\hline
\end{tabular}

\section{RESULTS AND DISCUSSION}

\subsection{Characterization of mango seed oil}

The Physicochemical analyses of the oil are as shown in table 3.0. The free fatty acid (FFA) content of the mango seed oil was not within the specified ASTM standard for fatty acid ethyl ester production of $<1 \%$, thus acid esterification was carried out to reduce the FFA content.

Table 3.0: Physicochemical Properties of the extracted mango seed oil.

\begin{tabular}{|c|c|}
\hline Properties & Values \\
\hline Specific gravity & 0.8776 \\
\hline$\%$ Moisture content & 0.5000 \\
\hline Acid Value $(\mathrm{mg} \mathrm{NaOH} / \mathrm{g})$ & 21.0300 \\
\hline Free fatty Acid $(\mathrm{mg} \mathrm{NaOH} / \mathrm{g})$ & 10.5250 \\
\hline Saponification value $(\mathrm{mg} \mathrm{NaOH} / \mathrm{g})$ & 207.5700 \\
\hline Ash content $(\mathrm{mg} \mathrm{NaOH} / \mathrm{g})$ & 1.0000 \\
\hline Iodine Value $\left(\mathrm{I}_{2} \mathrm{~g} 100 \mathrm{~g}^{-1}\right)$ & 7.1100 \\
\hline Cloud point $\left({ }^{\circ} \mathrm{C}\right)$ & 31.0000 \\
\hline
\end{tabular}

\begin{tabular}{|c|c|}
\hline Refractive index & 1.4670 \\
\hline Viscosity (cP) & 2.6000 \\
\hline
\end{tabular}

\subsection{Characterization of Fatty acid ethyl ester}

The fuel properties of fatty acid ethyl ester were characterized by their viscosity, density, Cetane number, Cloud and pour points, ash content, acid value, etc. However, the ethyl ester produced under optimum condition of 6:1 ethanol/oil molar ratio with acid-base catalytic-method at temperature of $65^{\circ} \mathrm{C}$ in 1hour was analyzed in respect to some significant properties of diesel fuel as mentioned above. Most of these properties conformed to Biodiesel Standard of (ASTM D6751), Table 3.1 specifies the quality for pure biodiesel (B100) and the international standard, EN 14214, and describes the minimum requirements for biodiesel produced from different feed stocks. These standards are shown in Table 3.1. The cloud point and pour point of ethyl ester showed higher values in comparison to the conventional diesel fuel which may have resulted from the high stearic acid content of mango seed oil and also the temperature at which a liquid fatty material becomes cloudy due to the formation of crystals and solidification of saturant. In order for this diesel to be adopted as a substitute to petroleum-based diesel, the fuel line should be heat-traced to maintain acceptable viscosity of the diesel. The addition of ethanol in biodiesel helps to reduce the kinetic viscosity of biodiesel as seen from table 3.0 and 3.1 .

Table 3.1: Comparison of the ethyl ester (biodiesel) produced and the conventional Diesel

\begin{tabular}{|c|c|c|c|c|c|}
\hline Parameter & Values & Unit & $\begin{array}{c}\text { ASTM } \\
\text { Specifications } \\
\text { (D6751) }\end{array}$ & $\begin{array}{c}\text { EN } \\
14214\end{array}$ & $\begin{array}{c}\text { N0.2 } \\
\text { DIESEL }\end{array}$ \\
\hline $\begin{array}{c}\text { S.G. } \\
60 / 60^{\circ} \mathrm{F}\end{array}$ & 0.87 & - & $0.80-0.90$ & $\begin{array}{c}1.9- \\
6.00\end{array}$ & $820-860$ \\
\hline $\begin{array}{c}\text { Iodine } \\
\text { Value }\end{array}$ & 39.20 & $\begin{array}{c}\left(\mathrm{I}_{2} \mathrm{~g} 100 \mathrm{~g}^{-1}\right. \\
\text { oil })\end{array}$ & & $120 \mathrm{max}$ & - \\
\hline $\begin{array}{c}\text { Ash } \\
\text { Content }\end{array}$ & 0.12 & - & & & - \\
\hline $\begin{array}{c}\text { Acid } \\
\text { Value }\end{array}$ & 0.35 & $\mathrm{mgNaOH} / \mathrm{g}$ & & $0.5 \mathrm{max}$ & - \\
\hline $\begin{array}{c}\text { Cloud } \\
\text { point }\end{array}$ & 32.00 & ${ }^{\circ} \mathrm{C}$ & & -19 to -8 \\
\hline $\begin{array}{c}\text { Kinematic } \\
\text { viscosity } \\
@ 400^{\circ} \mathrm{C}\end{array}$ & 5.92 & $\mathrm{~mm}^{2} \mathrm{~s}^{-1}$ & $1.9-6.0$ & $3.5-5.0$ & $2.5-3.5$ \\
\hline $\begin{array}{c}\text { Pour point } \\
\text { ( } 28.00\end{array}$ & ${ }^{\circ} \mathrm{C}$ & & & -34 to - \\
\hline $\begin{array}{c}\text { Cetane } \\
\text { number }\end{array}$ & 53.20 & - & $47 \mathrm{~min}$ & $51 \mathrm{~min}$ & $49-55$ \\
\hline $\begin{array}{c}\text { Flash } \\
\text { point }\end{array}$ & 173.50 & ${ }^{\circ} \mathrm{C}$ & $130 \mathrm{~min}$ & $>101$ & $>55$ \\
\hline
\end{tabular}

\subsection{Effects of process variables on mango seed ethyl ester} yield.

The effect of different process variables on the yield of mango seed oil ethyl ester were studied as shown in table 2.0 above. The results revealed that the yield of ethyl ester increased with 
increase in molar ratio up to $6: 1$ and that temperature of $65^{\circ} \mathrm{C}$, reaction time of 1 hour with molar ratio of $6: 1$ of ethanol/oil were the best condition for transesterification reaction of mango seed to biodiesel fuel as could be seen in figure $3.0-$ 3.3 below.
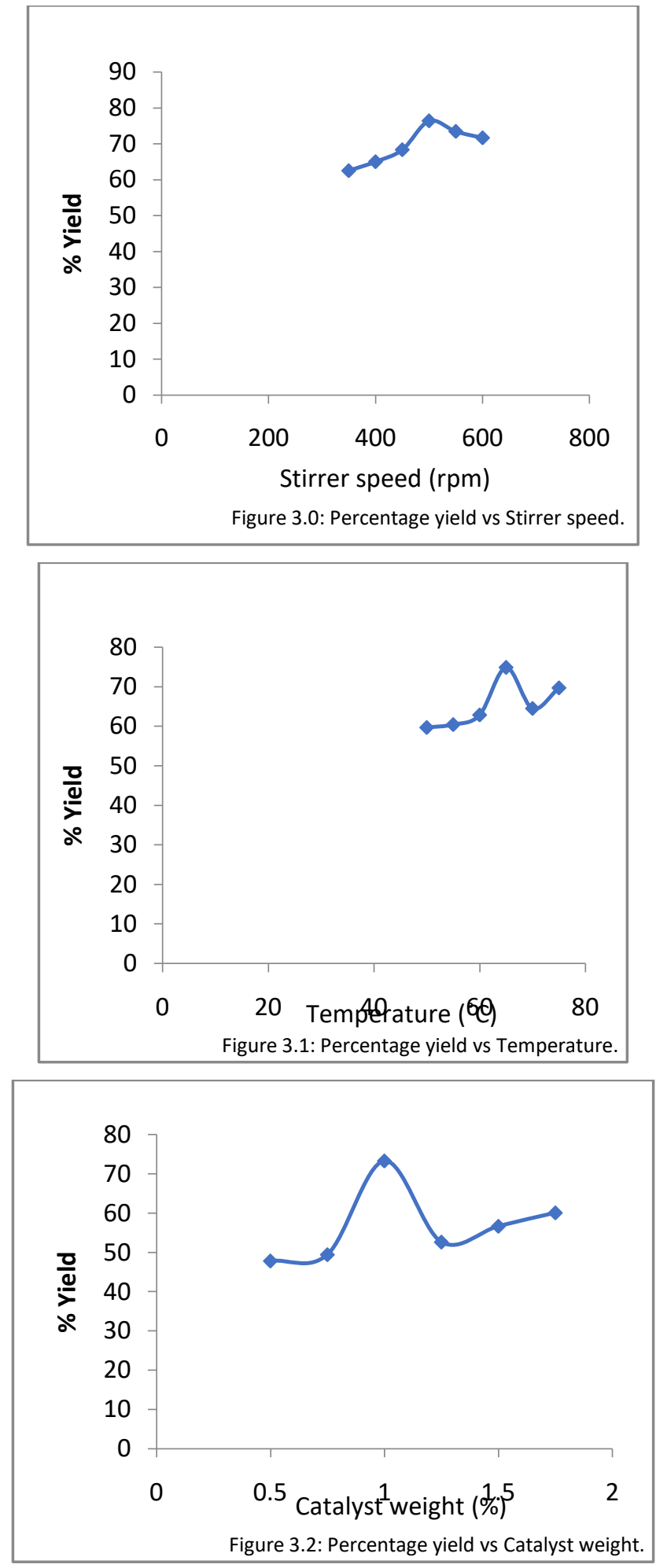

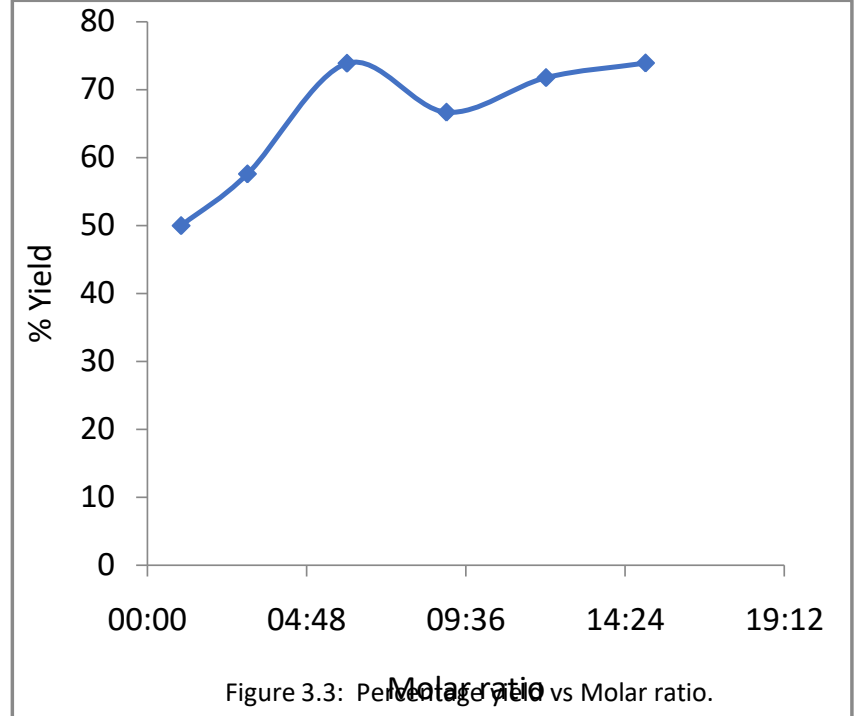

The result showed that yield of mango seed oil increased with increase in temperature which is in agreement with the work of [9], it was showed that higher reaction temperature helped in faster settlement of glycerol. Heating at a higher temperature also lowered the viscosity of the oil. Increase in temperature increased the yield of ethyl ester and decreased the reaction time, in agreement with the work of [6].

It was observed that the yield increased as the reaction proceeded until a catalyst weight of $1 \%$ was reached. The yield of ethyl ester became virtually constant after $1 \%$ of the catalyst weight was reached, indicating that the optimum catalyst weight was $1 \%$. This could be seen in figure 3.2 above. Ref. [12] had shown that the conversion rate of biodiesel increased with increase in catalyst concentration.

The stirring speed appears to be of particular importance for the transesterification reaction, it ensures homogeneity within the reaction mixture and also increases the contact area between the oil, sodium hydroxide and ethanol solution. The yield was observed to decrease as stirring rate went above 500rpm; the backward reaction may have been favored when the mixing intensity was accelerated. The yield of ethyl ester at $500 \mathrm{rpm}$ was $76.37 \%$ after 1 hour of reaction. The results are in conformity with observations made by [16],[17] who studied the effect of agitation on transesterification reaction of vegetable oil and concluded that higher agitation promoted the homogenization of the reactants and thus led to higher yields.

\subsection{Kinetics of Transesterification reaction of Mango Seed Oil}

The kinetics of oil extracted from mango seeds were studied at different temperatures, stirrer speed, ethanol/oil molar ratio and catalyst concentration. The experiments were performed by varying the process parameter one at a time. Firstly, the reaction temperatures were varied between $50^{\circ} \mathrm{C}$ to $75^{\circ} \mathrm{C}$, while maintaining other transesterification reaction factors constant. It was observed that the reaction rate was very fast at the beginning (first 20 minutes) and reduces with reaction time. The rate of reaction was virtually constant after 1 hour 
and at a reaction temperature of $65^{\circ} \mathrm{C}$, showing that the optimum reaction temperature and reaction time was $65^{\circ} \mathrm{C}$ and I hour respectively. This same trend was observed when reaction temperature was kept constant and varying other transesterification reaction factors such stirrer speed, catalyst concentration and ethanol/oil molar ratio. It was also observed that the maximum reaction rate was obtained at a stirrer speed of 500rpm, catalyst concentration of $1 \%$ and ethanol/oil molar ratio of $6: 1$ and after a reaction time of 1 hour.

In order to determine the kinetic model that will fit the experimental results, the first order kinetic model was first tested with the experimental data by plotting $\ln \left(\mathrm{C}_{\mathrm{AO}} / \mathrm{C}_{\mathrm{A}}\right)$ against time as shown in figure 3.4. If the reaction was first order, a straight-line graph passing through the origin would have been obtained. The work did not show a linear relationship of $\left[\ln \left(\mathrm{C}_{\mathrm{AO}} / \mathrm{C}_{\mathrm{A}}\right)\right]$ as a function time, indicating that the experimental results did not fellow a first order kinetic model. Second order kinetics was investigated by plotting a graph of $1 / C_{A}$ against reaction time as shown in figure 3.5, which gave a straight-line graph with a positive slope and intercept, indicating that the transesterification reaction of the triglycerides in mango seed oil conforms to second order. The transesterification reaction rate constant, $\mathrm{k}$, and the coefficient of determination, $\mathrm{R}^{2}$ were determined according to the linear curves. For this second order system, the activation energy was also determined by plotting a graph $\ln \mathrm{k}$ versus $1 / \mathrm{t}$ and equating the slope with (-E/R) according to Arrhenius relationship. The data are shown in table 3.2 and in figure 3.7.

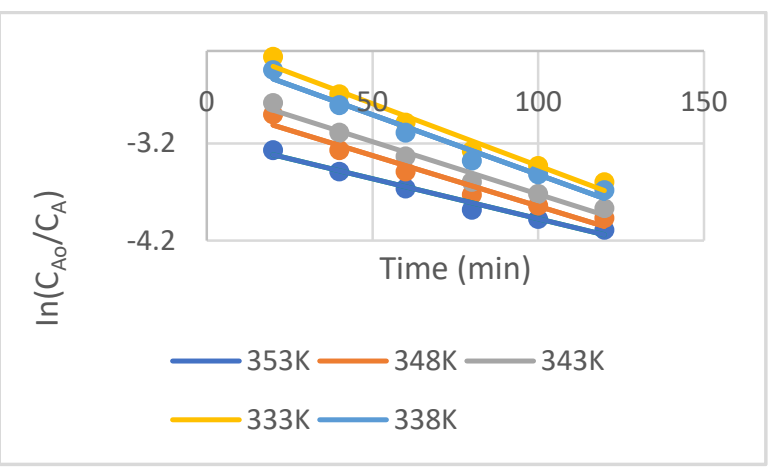

Fig. 3.4: First-order kinetics plot for the synthesis of mango seed ethyl ester

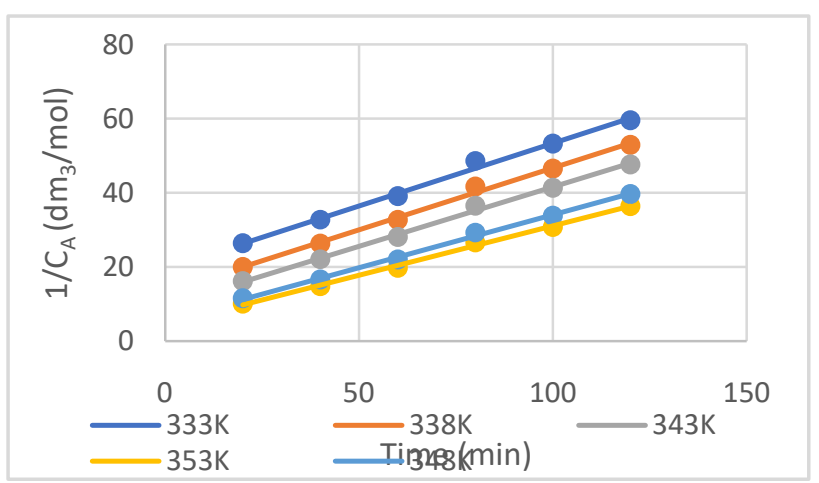

Fig. 3.5: Second-order kinetics plot for the synthesis of mango seed ethyl ester
Table 3.1: Reaction rate constants and regression values at various temperatures

\begin{tabular}{|c|c|c|c|c|}
\hline $\begin{array}{c}\text { Temperatur } \\
\mathrm{e}(\mathrm{K})\end{array}$ & \multicolumn{2}{|c|}{ First order } & \multicolumn{2}{c|}{ Second order } \\
\hline & $\begin{array}{c}\mathrm{K}, 1^{\text {st }} \\
\mathrm{min})-1\end{array}$ & $\mathrm{R} 2$ & $\begin{array}{c}\mathrm{K}, 2 \mathrm{nd} / \mathrm{wt} \\
\% \mathrm{wt} / \mathrm{wt} \\
\mathrm{min}^{-1}\end{array}$ & $\mathrm{R} 2$ \\
\hline 333 & -0.0127 & 0.9717 & 0.3386 & 0.9929 \\
\hline 338 & -0.0123 & 0.9716 & 0.3345 & 0.9955 \\
\hline 343 & -0.0128 & 0.9735 & 0.3196 & 0.9964 \\
\hline 348 & -0.0104 & 0.9571 & 0.2854 & 0.9974 \\
\hline 353 & -0.0082 & 0.9782 & 0.2660 & 0.9972 \\
\hline
\end{tabular}

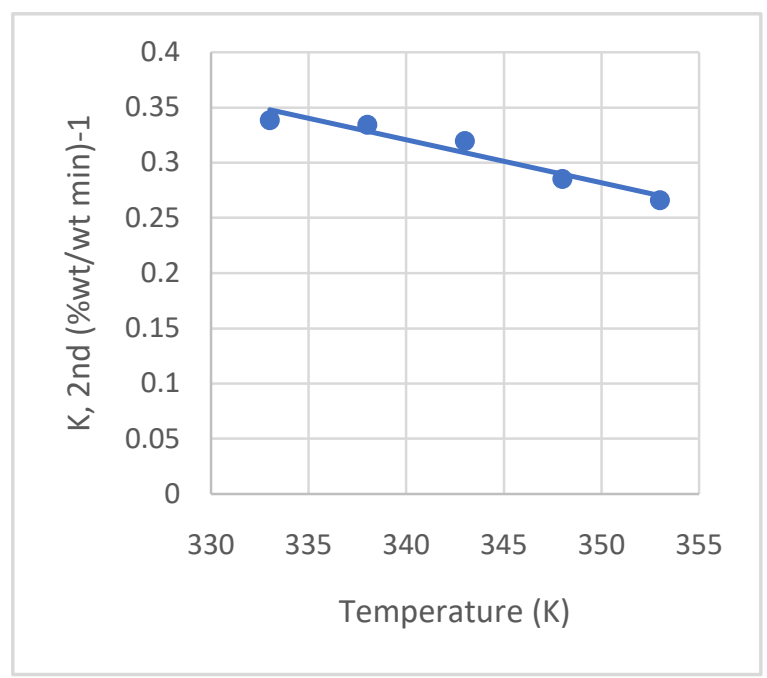

Fig.3.6: Overall second order kinetics model for the synthesis of mango seed ethyl ester at various temperatures

Table 3.2: Linearization of second order transesterification kinetic model of mango seed oil at varied temperature

\begin{tabular}{|c|c|c|c|}
\hline $\begin{array}{c}\mathrm{k} \\
\left(\mathrm{dm}^{3} / \mathrm{mol}\right. \\
\left.\mathrm{min}^{-1}\right)\end{array}$ & In $\mathrm{k}$ & $\mathrm{T}(\mathrm{K})$ & $1 / \mathrm{T}(1 / \mathrm{K})$ \\
\hline 0.029 & -3.533 & 323 & 0.00309 \\
\hline 0.057 & -2.861 & 328 & 0.00304 \\
\hline 0.0073 & -2.62 & 333 & 0.003 \\
\hline 0.100 & -2.3 & 338 & 0.00296 \\
\hline 0.319 & -1.141 & 343 & 0.00291 \\
\hline 0.307 & -1.182 & 348 & 0.00287 \\
\hline
\end{tabular}

A plot of $\ln \mathrm{k}$ against inverse of temperature was plotted as shown in figure 3.6. This plot is used to determine the activation energy required using Arrhenius equation. The linearization of Arrhenius equation is as shown below

$$
\mathrm{k}=\mathrm{Z} \mathrm{e}^{-\mathrm{E}_{\mathrm{a}} / \mathrm{RT}}
$$


Where, $\mathrm{k}$ is the rate constant

- $\mathrm{E}_{\mathrm{a}}$ is the activation energy

- $\quad \mathrm{R}$ is the gas constant $(8.314 \mathrm{~J} / \mathrm{mol}-\mathrm{K})$

- $\mathrm{T}$ is temperature in Kelvin

- A is pre-exponential factor or Arrhenius factor

- Linearizing,

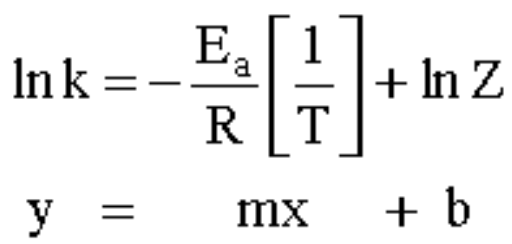

Then, the activation energy $E_{a}$ was calculated from the line gradient as $94.23 \mathrm{~kJ} / \mathrm{mol}$.

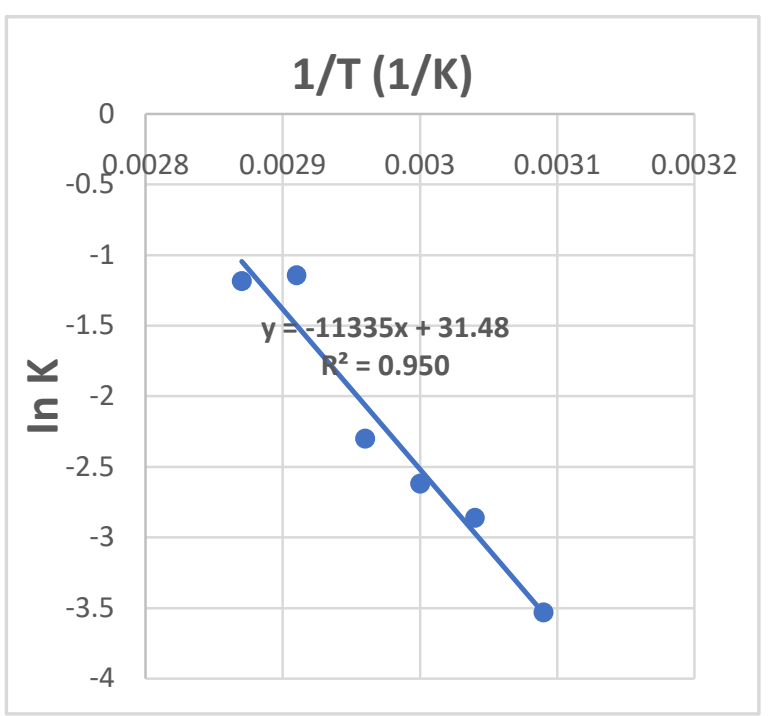

Figure 3.7: Plot of In K against (1/T) for activation energy calculation

Table 3.3: Activation energy for the synthesis of mango seed oil ethyl ester in comparison with another biodiesel

\begin{tabular}{|c|c|c|}
\hline Authors & $\begin{array}{c}\text { Biodiesel } \\
\text { feedstock }\end{array}$ & $\begin{array}{c}\text { Activation energy } \\
(\mathrm{kJ} / \mathrm{mol})\end{array}$ \\
\hline This work & $\begin{array}{c}\text { Mango seed } \\
\text { oil }\end{array}$ & 94.23 \\
\hline Gan et al., (2012) & Palm oil & 15.84 \\
\hline Berrios et al., (2007) & sunflower & 50.75 \\
\hline Liu et al., (2010) & soybean & 40.17 \\
\hline
\end{tabular}

The activation energy for the production of mango seed ethyl ester was obtained as $94.23 \mathrm{~kJ} / \mathrm{mol}$. Higher activation energy may signify a slower rate of reaction as compared to lower activation energy; the higher activation energy of mango seed ethyl ester reaction implies that the transesterification reaction occurred slowly at designated temperatures. The values of activation energy were higher because the reactions took place at lower temperatures and therefore were more sensitive to temperature changes as compared to that of other studies.

\section{CONCLUSION}

Fatty acid ethyl ester was successfully synthesized from mango seed oil using ethanol. The reaction followed a second order kinetic model with an overall rate constant of $3.9 \times$ $10-2\left(\% \mathrm{wt} / \mathrm{wt} \mathrm{min}^{\circ} \mathrm{C}\right)^{-1}$ and a regression value of 0.9504 . The activation energy for the production of mango seed ethyl ester was calculated as $94.23 \mathrm{~kJ} / \mathrm{mol}$.

The innovation in this study was the use of the mango seed oil with ethanol to produce biodiesel from $100 \%$ renewable energy sources to substitute methanol used for fatty acid methyl ester production which is gotten from fossil fuels.

\section{REFERENCES}

[1] Alamu, O.J. and Enweremadu, C.C. (2009). Development and Characterization of biodiesel from Shea nut butter. Int. Agrophysics, 2010, 24, 29-34.

[2] Athar, M., Zaidi, S. \& Hassan, S.Z. Intensification and optimization of biodiesel production using microwave-assisted acid-organo-catalyzed transesterification process. Sci Rep 10, 21239 (2020). https://doi.org/10.1038/s41598-020-777981

[3] Badifu G.I.O., (2011). Lipid Composition of Nigerian Butyrospermum paradoxum kernel. J. Food Comp. Anal., 2, 238244.

[4] Berrios M, Siles J, Martín MA, Martín A (2007) A kinetic study of the esterification of free fatty acids (FFA) in sunflower oil. Fuel 86(15):2383-2388. doi:10.1016/j.fuel.2007.02.002

[5] Bušić, A., Marđetko, N., Kundas, S., Morzak, G., Belskaya, H., Ivančić Šantek, M., Komes, D., Novak, S., \& Šantek, B. (2018). Bioethanol Production from Renewable Raw Materials and Its Separation and Purification: A Review. Food technology and biotechnology, 56(3), https://doi.org/10.17113/ftb.56.03.18.5546

289-311.

[6] Darnoko, D. and Cheryan, M. (2013). Kinetics of Palm Oil Transesterification in a Batch Reactor. Journal of American Oil Chemists' Society (JAOCS). Retrieved $2^{\text {nd }}$ May 2008 from http:/www.fineprint.com

[7] Freedman B, Butterfield RO, Pryde EH., (2009). Transesterification kinetics of soybean oil. J Am Oil Chem Soc; 63:1375-80.

[8] Gan S, Ng HK, Chan PH, Leong FL (2012) Heterogeneous free fatty acids esterification in waste cooking oil using ion-exchange resins. Fuel Process Technol 102(0):67-72. doi:10.1016/j.fuproc.2012.04.038

[9] Gupta P.K., Kumar R., Panesar B.S., and Thapar V.K., (2012). Parametric studies on biodiesel prepared from rice bran oil. Agric. Eng. Int.: CIGR Ejournal.

[10] Liu X, Piao X, Wang Y, Zhu S (2010) Model study on transesterification of soybean oil to biodiesel with methanol using solid base catalyst. J Phys Chem A 114(11):3750-3755. DOI: 10. $1021 /$ jp9039379

[11] Maranz S.Z., Wiesman J., Bisgaard J., and Bianchi G., (2011). Germplasm resources of Vitellaria paradoxa based on variations in fat composition across the species distribution range. Agroforestry Sys., 60, 71-76.

[12] Mittelbach M, Gangl S., (2007). Long storage stability of biodiesel made from rapeseed and used frying oil. J Am Oil Chem Soc; 78:573-7.

[13] Moina A. \& Sadaf Z, (2020). A review of the feedstocks, catalysts, and intensification techniques for sustainable biodiesel production. Journal of Environmental Chemical Engineering, Volume 8, Issue 6, ISSN 2213-3437, https://doi.org/10.1016/j.jece.2020.104523.

[14] Mulugetta Y., (2008). Evaluating the economics of biodiesel in Africa. Renewable and Sustainable Energy Review, 13, 159215989. 
[15] Ogbonnaya C. and Adgidzi P.P., (2010). Evaluation of some physicochemical properties of shea butter (Butyrospermum paradoxum) related to its value for food and industrial utilization. Int. J. Postharvest Technol. Innovation, 1(3), 320-326.

[16] Sahoo P.K., Das LM., Babu M.K.G., and Naik S.N., (2011). Biodiesel development from high acid value polanga seed oil and performance evaluation in a CI engine. Fuel, 86, 448-454.
[17] Shah, S., Sharma, S. and Gupta, M.N. (2012). Biodiesel Preparation by Lipase-Catalyzed Transesterification of Jatropha Oil. Journal of American Chemical Society, Energy and Fuels, 18, 154-159. 